\title{
Media Ecology and the Blurring of Public and Private Practices: A Case from the Middle East ${ }^{3}$
}

\author{
Chiara de Franco
}

Few 'regions' of the world have received as much media attention as the Middle East. Public discourses about regional (in)security have contributed to shaping common understandings of regional conflicts and ultimately of that region as a distinct political entity (Bilgin 2004). Not surprisingly, the role of the media in the escalation and internationalization of conflicts in the Middle East has been subject of a significant number of scholarly works (e.g., Wolfsfeld 1997; Gilboa 2012; Melki 2014; Seib 2007). Furthermore, it has been arguably in response to events in the Middle East - from the Arab Spring to the rise of ISIS - that International Relations as an academic discipline has seen a significant increase of publications and conferences revolving around the role of the media in international politics. Nevertheless, the role of the media in the Middle East (and more in general in international politics) has been studied mainly on the basis of mainstream and homogeneous understandings of what the media are and what they do in and to our societies. This paper seeks to shift the focus from media outlets and organisations to the media as environments, and from media content to media ecology, which should be understood as the communication systems "within which human culture grows, giving form to its politics, ideologies, and social organization" (Milberry 2012). It therefore asks if and how the media ecology affects the development of international practices, here defined as "socially meaningful patterns of action which, in being performed more or less competently, simultaneously embody, act out, and possibly

\footnotetext{
${ }^{3}$ The author wishes to thank Friedrich Kratochwil, Laura Roselle, Rasmus Gahrn-Andersen, the two anonymous reviewers and all the participants in the 2016 EWIS on 'Social Media: Puzzles and Possibility in/on IR' for their helpful comments on a previous version of this article.
} 
reify background knowledge and discourse in and on the material world" (Adler and Pouliot 2011, 6). To answer this question, the paper seeks to articulate a new approach to the study of the role of the media in international politics by creating a dialogue between the practice theoretical approach in International Relations (Adler and Pouliot 2011) and the medium theory in media studies (Meyrowitz 1985). The paper uses a case from the Middle East to explore the added value of such a new approach and to illustrate the need for a new research agenda in International Relations.

In the following, a sketch of the academic debates that have addressed the issue of the media's influence in international politics will be provided. In particular, three debates will be mentioned: The one surrounding 'media effects' in foreign policy (e.g. Bahador 2007; Cohen 1994; Robinson 2002; Strobel 1997), the one about the 'mediatization' of war (e.g. Cottle 2006; Hoskins and O'Loughlin 2010) and the one about the role of images in securitization processes (e.g. Friis 2015; Hansen 2016; Williams 2003). Second, it will be argued that while all these studies focus mainly on the content of the media, further attention should be instead given to the 'media ecology' and how it contributes to the emergence and change of international practices. In fact, it will also be argued that we cannot study international practices without taking the media ecology into account. In particular, it will be maintained that the media ecology creates constraints (or opportunities) to distinguish between (or blur) private and public dimensions of life and that this has repercussions on what we understand as competent behaviour. Transformations in the media ecology, therefore, may lead to the transformation of international practices (or the emergence of new ones) where appropriate and competent behaviour reconstitutes the private in the public (and vice versa).

To explore its core theoretical claims further, the paper discusses how an Israeli/Iranian movement catalysed by a Facebook (FB) page prompted the development of a Transnational Activist Network where people are brought together through shared private experiences. Far from being a fully-fledged case study, this example should be considered as a starting point for developing International Relations research agendas exploring the connection between media ecology and the articulation of public and private spaces in international practices. 
The debates

An exhaustive review of all scholarly works theorizing the role of the media in international politics is beyond the scope of this article. Only the main research strands defining the field will be accounted for. These can be grouped on the basis of the debates they address as well as the epistemology they build on. First, the literature on the socalled 'CNN Effect' will be discussed together with some more recent works about the 'Internet Revolution'. Then, the mediatization literature will be analysed with a special reference to those works that have focused on the mediatization of war. Finally, poststructuralist analysis of how securitization and mass-mediated images connect will be examined.

The first strand of research to be analysed here is the CNN Effect literature, which refers to scholarly works investigating if and how media coverage affects foreign policy making. Having flourished in the 1990s and early 2000s, this body of work reacted to the rise of all news $24 \mathrm{~h}$ satellite channels like CNN but it also draw on theories and analyses of the role of TV coverage in US military engagements, especially with reference to Vietnam. The CNN Effect literature developed not one but six different concepts offering explanations of how the media affect international politics (De Franco 2012). Four of them identify different types of media effects: the CNN Effect of course (Cohen 1994; Mandelbaum 1994; Kennan 1993; Entman 2000; Livingstone and Riley 1999; Robinson 2002; Strobel 1997), but also Agenda Setting (Ammon 2001; Entman 2000; Halloran 1991; Jakobsen 2000; Nye 1999; O’Heffernan 1993; Rose 2000), Real Time Policy (McNair 1999; Nye 1999; O’Heffernan 1993), and Media Diplomacy (Katz, Dayan and Motyl 1984; Gilboa 2002; O’Heffernan 1993; Seib 1997). The other two, namely Indexing (Hallin 1989) and Consent Manufacturing (Herman and Chomsky 1988), basically argue against any assumption that media affect politics and instead explain how media content mirrors political discourses (indexing) or is radically shaped by them (consent manufacturing).

Scholarly debates about the Internet have developed from these very notions, even if other labels have sometimes been used to mark a difference with the past (i.e. digital diplomacy instead of media diplomacy). On the one hand, the Internet Revolution thesis builds on the belief that the media can finally affect politics because the way online content is produced makes it more difficult for political and economic elites to manufacture 
consent or to media outlets to simply 'index' political issues. Scholars supporting this view have argued that the Internet has transformed the public sphere through the opening of new multi-directional information flows and the 'democratization' of the media content (e.g. Benkler 2006; Chadwick 2006; Johnson and Kaye 2004; Matheson 2004; Sunstein 2007; Trippi 2004). On the other hand, scholars rejecting the Internet Revolution thesis start from the assumption that the media mirrors social and political dynamics but not really affected by them. Anderson (2011), for example, has refused to consider the Arab Spring as a product of the new media and argued that explanations for what happened in Tunisia, Egypt and Libya have to be found in the economic grievances and specific social dynamics of those countries. Wolfsfeld et al. (2013) have instead applied Wolfsfeld's Media-Politics model (1997) to insist that the role of social media in collective action depends on the political environment in which they operate and that therefore significant increase in the use of the new media is much more likely to follow a significant amount of protest activity than to precede it.

The second relevant body of research to be discussed is the literature on the mediatization of war. Building on authors like Mazzoleni and Schulz (1999), Jansson (2002), Schulz (2004), Hjarvard (2004), and Strömbäck (2008) who define mediatization as the "process through which core elements of a social or cultural activity (like work, leisure, play etc.) assume media form" (Hjarvard, 2004, 48), this body of research investigates how mediatization affects contemporary warfare. Most famously, Hoskins and O'Loughlin (2010) argue for the emergence of a specific paradigm of war, which they call 'diffused warfare', as the outcome of media-driven processes. According to them, the 'mediatization of war', which is the transformation and reconstruction of war in a media form, transforms the knowledge about war which is then employed in all those practices where force and violence are used (De Franco 2012). This then triggers more diffused causal relations between action and effects, which create increasing uncertainty for policymakers. The media, in this respect, are a factor shaping perceptions, enhancing social chaos and complexity, and making the relationship between the government and the public more unpredictable (De Franco 2012). Recently, however, the same authors have shown a strong disillusion about the transformative potential of the new media, as a consequence of governments' increasing ability to control the content available on the web and 'arrest' the diffusion of warfare (Hoskins and O'Loughlin 2015). 
Finally, a last body of research to be taken into account is the new emerging literature investigating the role of visual imagery in contemporary conflict and security and elucidating how visibility and securitization connect (e.g. Friis 2015; Kirkpatrick 2015; Hansen 2011, 2014 and 2016; Williams 2003). These studies reject the positivist epistemology of the CNN Effect literature as problematic and instead of tracing causal relationships between media products and policy-making, they clarify how images are circulated, recognized and made part of the politics of war. The visual is approached as "an ontological-political condition rather than a variable" (Hansen 2011, 52), and an attempt is made to understand how the visibility of war becomes part of securitization processes. Friis (2015), for example, has explained how in the US and the UK, ISIS beheading videos have shaped "the political terrain in which decisions about war and peace have been produced and legitimized" (Friis 2015, 728).

Despite notable differences, the three bodies of literature sketched above share a common starting point: they all move from an essential interest in the content of the media. As a consequence, attention is paid uniquely to the message and to the conditions of its production and circulation, forgetting Marshall McLuhan's lesson that the medium is the message (McLuhan 1964) and that attention should be paid also to the environment that communication technologies generate. ${ }^{4}$

\section{From media content to media ecology}

Following the medium theory (Meyrowitz 1985), this paper argues that the form in which people communicate has an impact that goes beyond the choice of specific messages, because the media are not simply channels for conveying information between two or more environments, but rather environments in and of themselves. McLuhan (1964) explained how the media impose themselves upon all levels of our private and social lives and how this process creates a sensory environment as invisible to us as water is to fish, that is, an ecology of sorts. Thus, the media become extensions of the human senses and affect the organization of perception, feeling, and understanding. As a consequence, theorising the place of the media in our societies requires going beyond

\footnotetext{
${ }^{4}$ Even the works on the mediatization of war, which do take the media ecology into consideration, end up paying attention to the media content as the starting point to understand the media logic and the way this affects social or cultural activities more than to the media as environment.
} 
the study of media coverage and paying attention to the 'media ecology', which in turn implies studying the collision of communication technologies, culture and consciousness. By combining the bodies of work of McLuhan and Erving Goffman, Meyrowitz (1985) has argued that to understand the impact of the media on social behaviour we must start from the concept of social 'situation'. This can be understood as a 'system of information', that is "a given pattern of access to social information, a given pattern of access to the behaviour of other people" (Meyrowitz 1985, 37). As "information systems', instead of physical settings as understood by most of the situationists, a society's set of social situations can be modified without building or removing walls and corridors and without changing customs and laws concerning access to places. The introduction of a widespread medium of communication alters the media ecology and "may restructure a broad range of situations and require new sets of social performances" (Meyrowitz 1985, 39). In fact, while the separation of people in different situations produces specific beliefs, worldviews and behaviours, the merging of those situations and related actors and audiences will produce new beliefs and behaviours. The media therefore affect social actions because they rearrange the division between different situations, in terms of both actors and audiences, and change the notion of appropriate behaviour for each situation. When previously distinct social situations are combined by a new medium (such as the radio, TV etc.), then a behaviour that was considered as appropriate can well become inappropriate and vice versa. Meyrowitz explains:

"Electronic media have rearranged many social forums so that most people now find themselves in contact with others in new ways. And unlike the merged situations in face-to-face interaction, the combined situations of electronic media are relatively lasting and inescapable, and they therefore have a much greater effect on social behaviour" (Meyrowitz 1985, 5).

The media, in sum, construct and shape new social situations by building bridges between the existing ones. This is not to be understood as technological determinism because the 'medium' theorists have never neglected the transformative potential of human agency ${ }^{5}$ and have in fact emphasized the interaction of communication, culture, and consciousness.

\footnotetext{
${ }^{5}$ See for example how McLuhan discusses IBM's role in defining the 'message' of computer technology (McLuhan 1964, 9).
} 
Reading Meyrowitz today can be quite striking. Almost everything he wrote about the advent of TV sounds all too familiar, all too echoing recent academic and journalistic pieces about the Internet. The application of medium theory to the Internet might be contested on the basis of the fact that the Internet is not a single medium, nor does it use a single technology. In fact, the Internet is made of a synergic network of different media and technologies which create so many information environments that a complete list is virtually impossible: online newspapers, TVs or radios, the blogosphere, the social networks, online telephoning systems, information/picture/video sharing platforms like YouTube, etc. Nevertheless, the lessons of the medium theory remain valid in so far as it pushes us to study not just a new medium but also the new media ecology (Postman 2000). This also makes it necessary to go beyond mainstream distinctions between 'old' (print, radio, TV) and 'new' media (digital media) since they do not live in separate universes but in a common ecology.

The argument here is that analysing the media ecology is necessary to understand how international practices and therefore international politics emerge as distinct phenomena in the first place. Opening a dialogue between medium theory and the practice theoretical approach to International Relations can help clarifying this point. In fact, an in-depth analysis of these two approaches, which developed in separate disciplinary realms, reveals a great potential for cross-fertilization. A common element in the varied contributions to the practice theoretical approach seems to be a call for studying social actions by taking practice as the fundamental unit of analysis and move away from models of action that focus on the calculation of interests or the evaluation of norms (see, e.g. Adler and Pouliot 2011; Bueger and Gadinger 2015). The practice turn is said to imply "emphasizing process, developing an account of knowledge as action, appreciating the collectivity of knowledge, recognizing the materiality of practice, embracing the multiplicity of orders, and working with a performative understanding of the world" (Bueger and Gadinger 2015, 449). Thus, on the one hand, what is interesting to these analysts are "concrete situations of life in which actors perform a common practice and thus create and maintain social orderliness" (Bueger and Gadinger 2015, 451) as well as change and the emergence of new practices (Adler-Nissen 2015). For practice theorists, "the intentions and motivations of actors are less relevant. Their actual activities and practical enactments in concrete situations matter. In other words, situations become 
more significant than actors" (Bueger and Gadinger 2015, 451). On the other hand, medium theory suggests that we cannot understand social situations without taking the media ecology into consideration. This also means that changes to international practices might develop from the continuous co-constitution of media ecology and social situations. In this context, the new media ecology can be understood as transformative not only because it blurs the distinction between media consumers and producers and allows new agents to participate in international practices, but also because it transforms social situations, notions of appropriate and competent behaviour, and therefore the form of social interaction underpinning international practices. In particular, this paper intends to argue that in the new media ecology traditional boundaries between private and public spaces are blurred and that this has profound implications for how we understand and practice international politics.

\section{Reconstituting private and public spaces}

According to Meyrowitz, the traditional distinctions between people's 'onstage' and 'backstage' behaviours, which Goffman wrote about, built on the separate information worlds, which the printed media allowed for. Social and technological processes have progressively altered traditional separations between public, restricted, and secret spaces. What was supposed to be accessible to a restricted group of people has been progressively made into something visible to anybody. By showing everything to everybody, the electronic media first and the digital media later have contributed to altering social interaction and have been altered by it in return. In his view, the electronic media have enlarged the 'onstage' area and as a consequence behaviours that were once kept 'backstage' are reconstituted as 'onstage'. In Meyrowitz's own words, “the behaviour exhibited in this mixed setting would have many elements of the behaviour from previously distinct encounters, but would involve a new synthesis, a new pattern - in effect, a new social order" (Meyrowitz 1985, 6). Thus, a new 'middle region' behaviour emerges with a backstage bias. This should be understood as taking place through social practices, which at the same time transform traditional understandings of competent onstage and backstage behaviour and are transformed by the emergence of new 'middle region' situations. The Internet plays an important role in such a process because by using it people have put and found themselves in contact with others, in new ways or to a differ- 
ent degree. In particular, the social media seem to offer the opportunity for a social restructuring where online encounters substitute face-to-face meetings, where people have at the same time more opportunities to construct their own image and identity and less control on what is visible and to which audiences. This implies that a neat distinction between onstage or backstage becomes more and more difficult and that most social practices develop in middle region situations.

This is of crucial importance for the evolution of international practices if we recognize that the articulation of private and public realms is key to the understanding of their very emergence (as very well explained by Kratochwil (2011) in his discussion of the inter/external and private/public nexus and by Abrahamsen and Williams (2011) in their discussion of security as a field of practice). Also scholars not belonging to the "practice turn' have provided other important clues on this matter. Horowitz (1982), for example, has pointed out that the emergence of the nation-state and theories and practices of sovereignty caused "a distinctly public realm [...] to crystallize" (Horowitz 1982, 1423). On the other hand, the private realm of 'civil society' emerged as a "reaction to the claims of monarchs and, later, parliaments to the unrestrained power to make law" (Horowitz 1982, 1423), and therefore as a "countervailing effort to stake out distinctively private spheres free from the encroaching power of the state" (Horowitz 1982, 1423). Liberal understandings of natural-rights and free trade and consequent legal practices came to strengthen such a distinction that found clear expression in the "separation between constitutional, criminal, and regulatory law - public law - and the law of private transactions - torts, contracts, property, and commercial law" (Horowitz 1982, 1424). In reality, more than a neat separation of public and private, what Horowitz seems to describe is a dynamic process where public and private are redefined continuously and mutually. Such a process has been seen as being integral to the development of diplomacy (Anderson 1993) as well as to the very understanding of politics in relation to gender (Elshtain 1993) and 'the social' (Owens 2015).

By focusing on practices as visible on FB, the following pages will further clarify how the new media ecology contributes to the articulation of public and private and with what possible consequences on international practices. Originally conceived to serve interpersonal communication, FB has progressively evolved into an online public space for political discussion (among other things). In so doing, it has significantly re- 
shaped the meaning of onstage and backstage in relation to friendship and other kinds of private relationships, but also blurred the division between onstage and backstage spaces in relation to political activism. Such changes have partly been led by how FB creators have originally designed the social network and continued to develop it, but they emerge also from how users are often appropriating it "despite the intent of [its] creators and in the face of determined attempts by the state to use [it]" (Aouragh and Alexander 2011, 1345).

A case of political activism will be used to explore the core thesis of this article. Further research is necessary to develop a fully-fledged case study, especially because following the practice theoretical approach, ethnographic research should be conducted to complete the analysis. To at least partly overcome such limitation, the analysis presented here is mainly based on interpretative digital-ethnographic methods (e.g. Coleman 2010; Murthy 2011), which compared to discourse analysis, shift the focus from the text to the practice - as observable with the simultaneous capture of verbal, audio, and visual texts. This is no solution for the lack of those thick descriptions of individuals, groups, communities and interaction that can only be the product of traditional faceto-face ethnographic methods. Nevertheless, this strategy forces the researcher to remain true to the ethnographic approach by, for example, recording a lot of observations as new interaction becomes visible online and independent of how relevant this is perceived at the time of the data collection (Murthy 2011). The FB page examined in the following analysis has been studied by the author through digital observation for about three years, which included following the initiatives and conversations taking place in the FB page but without any active engagement. In the next pages, some findings based on notes taken and reflections made in the past three years will be briefly presented.

Israel Loves Iran

In 2011, Israeli graphic designer Ronny Edry uploaded a poster to his FB profile depicting himself with his daughter holding the Israeli flag alongside the words "Iranians, we will never bomb your country, we [heart] you" (The Peace Factory 2012a). Attached to the poster there was a brief letter by Edry addressing the Iranian people: 
"To the Iranian people. To all the fathers, mothers, children, brothers and sisters. For there to be a war between us, first we must be afraid of each other, we must hate. I'm not afraid of you, I don't hate you. [...] If you see someone on your TV talking about bombing you, be sure he does not represent all of us. I'm not an official representative of my country. I'm a father and a teacher. I know the streets of my town, I talk with my neighbours, my family, my students, my friends and in the name of all these people, we love you. We mean you no harm. On the contrary, we want to meet, have some coffee and talk about sports. To all those who feel the same, share this message and help it reach the Iranian people" (The Peace Factory 2012a).

According to Edry's account, within hours tens of Israelis posted their own pictures with the same message and within twenty-four hours messages from Iran started pouring in, some as private messages, some as friend requests. Some did use their identities; others contacted Edry with their identities concealed. As Edry's post had received more than 7,000 likes he created the Israel-Loves-Iran FB page and blog together with his wife Michal Tamir and 'Pushpin Mehina', a small preparatory school for graphic design students. At this point Edry asked the Iranians who had contacted him to post photos of themselves as a reply to his original message and to all the other posters he and his wife had produced in the meantime. His Iranian contacts accepted to send him pictures but requested him to post them himself on his FB page as they felt they were running the risk of going to jail "over such a thing" (Yaron 2012). Within hours faceless portraits of Iranians sharing messages of love towards Israeli were posted onto the 'Israel Loves Iran' FB page and blog. An Iranian FB user even posted a direct message on the 'Israel Loves Iran' page:

"We also love you. Your words are reaching us despite the censorship. The Iranian people, apart from the regime, do not hold a grudge nor animosity against anyone, especially not the Israelis [...] We love you, love, peace. And thanks for your message" (The Peace Factory 2012a).

In the ten months since the FB page was created, it received over 100,000 'likes' and spawned a parallel movement headed by an Iranian graphic designer, Majid Nowrouzi, unsurprisingly called 'Iran Loves Israel'. The campaign then moved into a completely different phase, after a summit in Munich where Israelis and Iranians met each other to develop a joint plan. A non-profit, non-political organization was created in October 
2012, named The Peace Factory, and given the explicit goal of breaking down "the "iron curtain' between the people" (The Peace Factory 2012b) in the Middle East and "making connection between people, opening new communication line, making people get to know each other, re-humanize people from 'the other side'. Iranians, Palestinians, Israelis, Egyptians, Syrians, Lebanese, Turkish, Jordanians and more" (The Peace Factory 2012b).

Initially focused on mass media campaigns to "advertise "Peace in the Middle East" (The Peace Factory 2012b), including a campaign putting images of Israelis and Iranians on the sides of buses in Tel Aviv, The Peace Factory has slowly developed through new interactive practices taking place online, such as online meetings of Israeli and Iranian citizens or the sharing of portrait pictures, some of which have gone viral, like the one of a man and a woman kissing each other while holding their passports up to the camera: an Israeli passport and an Iranian passport respectively (Elgot 2012). Online activities thought have increasingly been complemented by offline practices too, which are promptly recorded using pictures and videos in a mixture of 'virtual' and 'real' encounters.

From an analytical point of view, the 'Israel loves Iran' initiative as well as The Peace Factory might seem as transnational networks developing from a quite naïf assumption that an increase in communication determines an increase in mutual understanding between the parties to a conflict. In reality, the name of the initiative tells the most important story here: The substance of the interaction between people on that page is sharing private experiences. Both promoters and participants in these initiatives see themselves as practicing political activism while sharing personal information, such as name, age, nationality and portrait pictures. On 'Israel loves Iran', rituals, symbols and forms of communication revolving around personal experiences and feelings are given political significance. Thus, Valentine's Day becomes a day for peace (FB post 14 February 2016); pictures of straight and gay couples are used to show that love equals peace (see, e.g. FB post 30 January 2016); pictures of friends that met on line through the FB page and then became friends off line are posted to show that friendship equals peace (see, e.g. FB post 11 January 2016); stories of private love and loss are collected with the 'sandbox story' initiative; pictures taken by Edry in Tel Aviv and Faramarz in Teheran are juxtaposes to show private moments of people in the public spaces of the two 
cities with the 'Today/Tel Aviv/Teheran' initiative. If this might look as limited to practices related to the very production of the FB page's content, other practices emerge as essentially blurring private and public and constitutive of inter-personal interaction. Some examples could be found in the ' +1 ' campaign launched in September 2015 that connected about 60 people for (at least) one week of friendship, and the 'Friend me 4 Peace' and 'Coffee with you' initiatives that in the past two years have given members of the page the possibility of 'meeting' online, but also offline if possible. To participate in the 'Friend me 4 Peace' initiative, for example, people of any nationality only had to visit the 'Israel Loves Iran' FB page and post a 'friend me' request with information about their country of residence. The Peace Factory team had then to identify their profile picture and profession, and design and publish the post so that the members of the page could add them as a friend. In most cases, the person portrayed in the post was also quoted and normally stating not what they thought about the conflict, but how they 'felt' about having friends on the other side.

The messages conveyed by the 'Israel loves Iran' page, as well as the conversations taking place on the page tend to focus on the 'relationship' between members of the page. This is consistent with how FB is used more in general. Compared to TV communications as analysed by Meyrowitz, the interaction taking place on a FB page might seem as producing an even greater back region bias due to the fact that it becomes even more difficult to separate participation in private and public threads of experience in that specific environment. The audience of posts and comments is for members of a page difficult to identify and in many ways visible only through replies and further comments, but the way most FB users employ FB in their daily lives seems to push towards back region behaviour. This is, at least, what we can observe as happening in the page under examination. Members of 'Israel Loves Iran' use an 'expressive' language to establish an emotional relation with the other members of the page more than to transmit specific ideas. Their use of pictures can be read also as an attempt at communicating personal attributes and expressing feelings, more than given political positions. The tone of most discussions on 'Israel Loves Iran' is informal and modelled on 'among-friends' conversations, even if on FB there is clearly still room (and time) to control, manipulate and even edit expressions. 
While not reaching a particularly impressive number of people ('Israel Loves Iran' counts about 122.000 'likes' and 'Iran Loves Israel' about 33.000), the two FB pages seem to have set a model. Similar groups have been created, from 'Israel Loves Palestine' (about 16.000 likes) and 'Palestine Loves Israel' (about 15.000 likes) to the more recent 'Russia Loves Ukraine' (which now counts about 1100 likes) and 'Ukraine Loves Russia' (counting about 1000 likes). The way these groups emerge through the articulation of public interest and private experience is interesting because so far transnational advocacy networks have been understood as "networks of activists, distinguishable largely by the centrality of principled ideas or values in motivating their formation" (Keck and Sikkink 1999, 89). In contrast with such a definition, the network of activists gathering through FB pages and friendship connections under the 'country $\mathrm{x}$ loves country y' motto are distinguishable only on the basis of how they connect private and public experience of a conflict. The specific practices that identify this kind of advocacy network are constituted (and constitutive) of a continuous blurring of private and public where individual feelings about aspects of individuals' private lives are translated into public expressions of feelings about the conflict. In the FB environment the onstage space is significantly expanded and a middle region is produced by the very way in which the newsfeed puts together friends, acquaintances and different kinds of groups, including other political activists' pages. The kind of 'social situation', which is so constituted presents a backstage bias and brings typically backstage language and behaviour into a new form of 'political activism', which is different from traditional onstage political activism. In fact, it is a 'middle region' political activism. Clearly, the way FB has been designed and developed (also as a response to usage) has facilitated the emergence of these practices. However, they should not be understood simply as 'FB practices' as they play out also outside FB, on sister Twitter accounts for example, and most importantly also offline. They develop in a specific media ecology that includes FB but cannot be reduced to FB.

Studying the emergence of these practices is important, independent from their immediate political role in shaping, as in this paper's example, diplomatic relations between states or conflict transformation. Looking for a direct impact of these practices over politics would mean falling again in the 'media-effect' paradigm. Instead, we need 
to study these practices because they have a long-term transformative potential. They are 'every-day' practices performed by

\begin{abstract}
"seemingly ordinary or subordinate people, non-elite groups, including lowermiddle and middle classes, migrant labourers and diasporas whose lives are shaped by and shape the world politics 'from below', exploring their capacity to change their political, economic and social environment" (Adler-Nissen 2015).
\end{abstract}

\title{
Conclusions
}

This paper has argued that to understand the role of the media in international politics, research in the field should move beyond content-centred and effects-centred approaches and instead focus on the connection between media ecology and international practices. It has been claimed that we cannot study international practices without taking the media ecology into account, especially because the latter is critical to the articulation of private and public dimensions of life, which in turn has arguably important repercussions on what we understand as the realm of (international) politics. Finally, the paper has focused on the example of an Israeli/Iranian movement, which aims at using new communication technologies to foster peace by developing a transnational advocacy network where the participants are brought together by the very act of sharing their private experience of the conflict. Further empirical research is needed for a more substantial assessment of how the media ecology affects the articulation of private and public in international practices, but the paper provides some evidence that such a research agenda is not just viable but vital to further our understanding of international politics. This is especially important if we take seriously the invitation of the practice turn to study every-day practices as constitutive of that phenomenon that we call international politics.

\section{References}

Adler-Nissen, R 2015, 'What's the Theory in International Practice Theory?', International Studies Quarterly. Available at: 
http://www.isanet.org/Publications/ISQ/Posts/ID/4959/Whats-the-Theory-inInternational-Practice-Theory [Accessed 4 October 2016].

Abrahamsen, R and Williams, MC 2011, 'Privatization in Practice: power and capital in the field of global security', in: E Adler and V Pouliot (eds.), International Practices, Cambridge University Press, Cambridge.

Adler, E and Pouliot, V (eds.) 2011, International Practices, Cambridge University Press, Cambridge.

Ammon, RJ 2001, Global Television and the Shaping of World Politics: CNN, Telediplomacy and Foreign Policy, McFarland and Company, New York.

Anderson, L 2011, 'Demystifying the Arab Spring. Parsing the Differences Between Tunisia, Egypt, and Libya', Foreign Affairs, May/June 2011. Available at: http://www.foreignaffairs.com/articles/67693/lisa-anderson/demystifying-the-arabspring [Accessed March 2013].

Anderson, MS 1993, The Rise of Modern Diplomacy 1450-1919, Longman, London.

Ang, I 1991, Desperately Seeking the Audience, Routledge, London.

Aouragh, M and Alexander, A 2011, 'The Egyptian Experience: Sense and Nonsense of the Internet Revolution', International Journal of Communication, vol. 5, pp. 13441358.

Bahador, B 2007, CNN Effect In Action, Palgrave McMillan, New York.

Benkler, Y 2006, The Wealth of Networks: How Social Production Transforms Markets and Freedom, Yale University Press, New Haven.

Bilgin, P 2004, Regional Security in the Middle East: A Critical Perspectives, Routledge, New York.

Bueger, C and Gadinger, F 2015, 'The Play of International Practice', International Studies Quarterly, vol. 59, no. 3, pp. 449-460.

Chadwick, A 2006, Internet Politics: States, Citizens, and New Communication Technologies, Oxford University Press, New York.

Coleman, G 2010, 'Ethnographic Approaches to Digital Media', Annual Review of Anthropology, vol. 39, pp. 487-505.

Cottle, S 2006, Mediatized conflict: Developments in media and conflict studies, Open University Press, Maidenhead.

Cohen, B 1994, 'A View from the Academy, in: WL Bennet and DL Paletz (eds.), Taken by Storm, Chicago University Press, Chicago.

De Franco, C 2012, Media Power and the Transformation of War, Palgrave Macmillan, Basingstoke.

Elgot, J (2012), 'Israel Loves Iran: The Peace Campaign Against Middle East War That Began On Facebook, Huffington Post. Available at:

http://www.huffingtonpost.co.uk/2012/08/31/israel-loves-iran-facebook-ronnyedry_n_1846168.html? [Accessed 30 October 2016]

Elshtain, JB 1993, Public Man, Private Women. Women in Social and Political Thought, Princeton University Press, Princeton. 
Entman, RM 2000, 'Declaration of Independence. The Growth of Media Power after the Cold War', in: BL Nacos; RY Shapiro and P Isernia (eds.), Decision Making in a Glass House. Mass media, Public Opinion, and American and European Foreign Policy in the 21st Century, Rowman \& Littlefield, Lanham.

Friis, SM 2015, 'Beyond anything we have ever seen': beheading videos and the visibility of violence in the war against ISIS', International Affairs, vol.91, no. 4, pp. $725-746$.

Gilboa, E 2012, 'Covering Gaza, 2008-2009: An Israeli View', in: P Seib (eds.), AlJazeera English, Palgrave, New York: NY.

Gilboa, E 2002, 'Global Communication and Foreign Policy', Journal of Communication, vol. 52, pp. $731-748$.

Hallin, DC 1989, The "Uncensored War": The Media and Vietnam, University of California Press, Berkeley.

Halloran, R 1991, 'Soldiers and Scribblers: A Common Mission, in: JM Lloyd (ed.), Newsmen \& National Defence: is Conflict Inevitable?, Brassey's, Washington.

Hansen, L 2016, 'Reading comics for the field of International Relations: Theory, method and the Bosnian War', European Journal of International Relations. Early View.

Hansen, L 2014, 'How images make world politics: International icons and the case of Abu Ghraib', Review of International Studies, vol. 41, no. 2, pp. 263-288.

Hansen, L 2011, 'Theorizing the Image for Security Studies: Visual Securitization and the Muhammad Cartoon Crisis, European Journal of International Relations, vol. 17, no. 1, pp. 51-74.

Herman, ES and Chomsky, N 1988, Manufacturing Consent. The Political Economy of the Mass Media, Phanteon Books, New York.

Hindman, M 2009, The Myth of Digital Democracy, Princeton University Press, Princeton.

Hjarvard, S 2004, 'From Bricks to Bytes: the mediatization of a global toy industry', in: I Bondebjerg and P. Golding (eds.), European Culture and the Media, Intellect Books, Bristol.

Horowitz, MJ 1982, 'The History of the Pulic/Private Distinction', University of Pennsylvania Law Review, vol. 130, no. 6, pp. 1423-1428.

Hoskins, A and O'Loughlin, B 2015, 'Arrested war: the third phase of mediatization', Information, Communication \& Society, vol. 18, no. 11, pp. 1320-1338.

Hoskins, A and O'Loughlin, B 2010, War and Media: The Emergence of Diffused War, Polity, Cambridge.

Jakobsen, VJ 2000, 'Focus on the CNN Effect Misses the Point: The Real Media Impact on Conflict Management is Invisible and Indirect', Journal of Peace Research, vol. 37, no. 2, pp. 131-143.

Jansson, A 2002, 'The Mediatization of Consumption: Towards an analytical framework of image culture', Journal of Consumer Culture, vol. 2, no. 1, pp. 5-31. 
Johnson, TJ and Kaye, BK 2004, 'Wag the Blog: How Reliance on Traditional Media and the Internet Influence Credibility Perceptions of Weblogs Among blog Users', Journalism \& Mass Communications Quarterly, vol. 81 no. 3, pp. 622-642.

Livingstone, S and Riley J 1999, 'Television Picture in Multilateral Policy Decision Making', British International Studies Conference. Unpublished paper

Katz, E; Dayan, D and Motyl, P 1984, 'Television Diplomacy: Sadat in Jerusalem', in: G Gerbner and M Siefert (eds.), World Communication Handbook, Longman, New York.

Keck, ME and Sikkink. K 1999, 'Transnational advocacy networks in international and regional politics', International Social Science Journal, vol. 51, no. 159: pp. 89101.

Kennan, GF 1993, 'Somalia Through a Glass Darkly'. The New York Times, 30 September 1993.

Kirkpatrick, E 2015, 'Visuality, photography, and media in international relations theory: A review', Media, War \& Conflict, vol. 8 no. 2, pp. 199-212.

Kratochwil, F 2011, The Puzzle of Politics. Inquires into the genesis and transformation of international relations, Routledge, New York.

Lull, J 1990, Inside Family Viewing: Ethnographic Research on Television Audiences, Routledge, London.

Mandelbaum, M 1994, 'The Reluctance to Intervene', Foreign Policy, vol. 95, summer, pp. 3-18.

Matheson, D 2004, 'Weblogs and the Epistemology of the News: Some Trends in Online Journalism', New Media Society, vol. 6, no. 4, pp.443-468.

Mazzoleni, G and Schulz, W 1999, 'Mediatization' of Politics: A Challenge for Democracy?', Political Communication, vol. 16, no. 3, pp. 247-261.

McLuhan, M 1964, Understanding Media. The Extension of Man, McGraw-Hill, New York.

McNair, B 1999, An Introduction to Political Communication, Routledge, London.

Melki, J 2014, 'The interplay of politics, economics and culture in news framing of Middle East wars', Media, War \& Conflict, vol. 7, no. 2, pp. 165-186.

Meyrowitz, J 1985, No Sense of Place. The Impact of Electronic Media on Social Behaviour, Oxford University Press, New York, Oxford.

Milberry, K 2012, 'Media Ecology', in: P Moy (ed.) Communication, Oxford University Press, Oxford. Available at:

http://oxfordindex.oup.com/view/10.1093/obo/9780199756841-0054 [Accessed 4 October 2016]

Mossberger, K; Tolbert, CJ and McNeal, RS 2008, Digital Citizenship: The Internet, Society, and Participation, MIT Press, Cambridge.

Murthy, D 2011, 'Emergent digital ethnographic methods for social research', in: S Hesse-Biber (ed.), Handbook of Emergent Technologies in Social Research, Oxford University Press, New York. 
Nye, J 1999, 'Ridefinire la Missione della NATO nell'Era dell'Informazione', Rivista Della NATO, vol. 4, pp. 12-15.

O'Heffernan, P 1993, 'Sobering Thoughts on Sound Bites Seen 'Round the World', in: BS Greenberg and W Gantz (eds.), Desert Storm and the Mass Media, Hampton Press, Cresskill, N.J.

Owens, P 2015, Economy of force: counterinsurgency and the historical rise of the social, Cambridge University Press. Cambridge.

Postman, N 2000, 'The humanism of media ecology', in Proceedings of the Media Ecology Association, vol. 1, pp. 10- 16.

Robinson, P 2002, The CNN Effect: the Myth of News, Foreign Policy and Intervention, Routledge, London; New York.

Rose, M General Sir 2000, 'The Media and International Security', in: S Badsey (ed.), The Media and International Security, Frank Cass, London.

Scott, E 2004, "'Big Media" Meets the "Blogger": coverage of Trent Lott's Remarks at Strom Thurmond's Birthday Party'. Kennedy School of Government Case Program. Case 1731.

Seib, P 1997, Headline diplomacy: How news coverage affects foreign policy, Praeger, Westport.

Seib, P (ed.), 2007, New Media and the New Middle East, Palgrave Macmillan, New York.

Silverstone, R 1990, 'Television and Everyday Life: Towards and Anthropology of the Television Audience', in: M Ferguson (ed.), Public Communication: The New Imperatives, Future Directions for Media Research, Sage, London.

Strobel, WP 1997, Late-breaking Foreign Policy: The News Media's Influence on Peace Operations, United States Institute of Peace Press, Washington, D.C.

Strömbäck, J 2008, 'Four Phases of Mediatization: an analysis of the mediatization of politics', International Journal of Press/Politics, vol. 13, no. 3, pp. 228-246.

Sunstein, CR 2007, Republic.com 2.0, Princeton University Press, Princeton.

Trippi, J 2004, The Revolution Will Not Be Televised: Democracy, the Internet, and the Overthrow of Everything, Harper Collins, New York, NY.

Yaron, O 2013, 'Israel Loves Iran' initiative takes off on Facebook', Haaretz. Available at: http://www.haaretz.com/news/national/israel-loves-iran-initiative-takes-off-onfacebook-1.419384 [Accessed March 2014]

Williams, MC 2003, 'Words, Images, Enemies: Securitization and International Politics', International Studies Quarterly, vol. 47, no. 4, pp. 511-531.

Wolfsfeld, G 1997, The Media and Political Conflict, Cambridge University Press, Cambridge.

Wolfsfeld, G; Segev, E and Sheafer, T 2013, 'Social Media and the Arab Spring. Politics Comes First', The International Journal of Press/Politics, vol. 18, no. 2, pp. 115-137. 